\title{
A Moisture-Wicking Passive Radiative Cooling Hierarchical Metafabric
}

Xiaoshuang Zhang ${ }^{\dagger}$, Weifeng Yang ${ }^{\dagger}$, Zhuwang Shao ${ }^{\dagger}$, Yaogang Li ${ }^{\dagger}$, Yun Sü, Qinghong Zhang , Chengyi Hou ${ }^{\dagger, *}$, Hongzhi Wang ${ }^{\dagger}$

†State Key Laboratory for Modification of Chemical Fibers and Polymer Materials, College of Materials Science and Engineering, Donghua University, Shanghai 201620, P. R. China

$\$$ Engineering Research Center of Advanced Glasses Manufacturing Technology, Ministry of Education, Donghua University, Shanghai 201620, P. R. China

${ }^{z}$ College of Fashion and Design, Donghua University, Shanghai 200051, P. R. China 


\section{Supporting Figures}
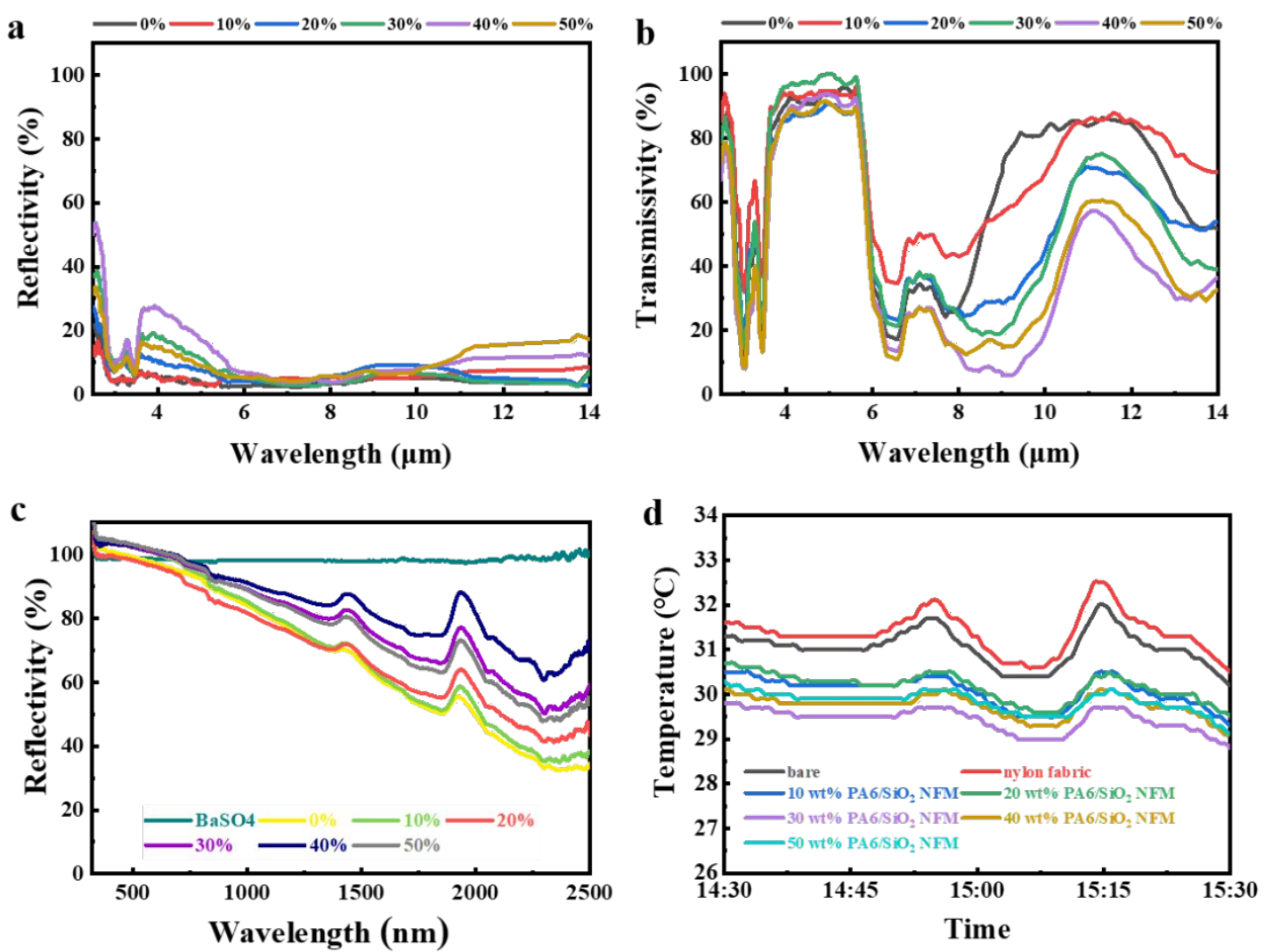

Figure S1. (a) IR reflectivity, (b) IR transmissivity and (c) UV-VIS-NIR reflectivity spectra. (d) Daytime cooling effect of the $\mathrm{PA} 6 / \mathrm{SiO}_{2}$ nanofiber membrane (NFM) with different mass ratios of $\mathrm{SiO}_{2}$. The results showed that the optimal mass ratio of $\mathrm{SiO}_{2}$ was $30 \%$. 

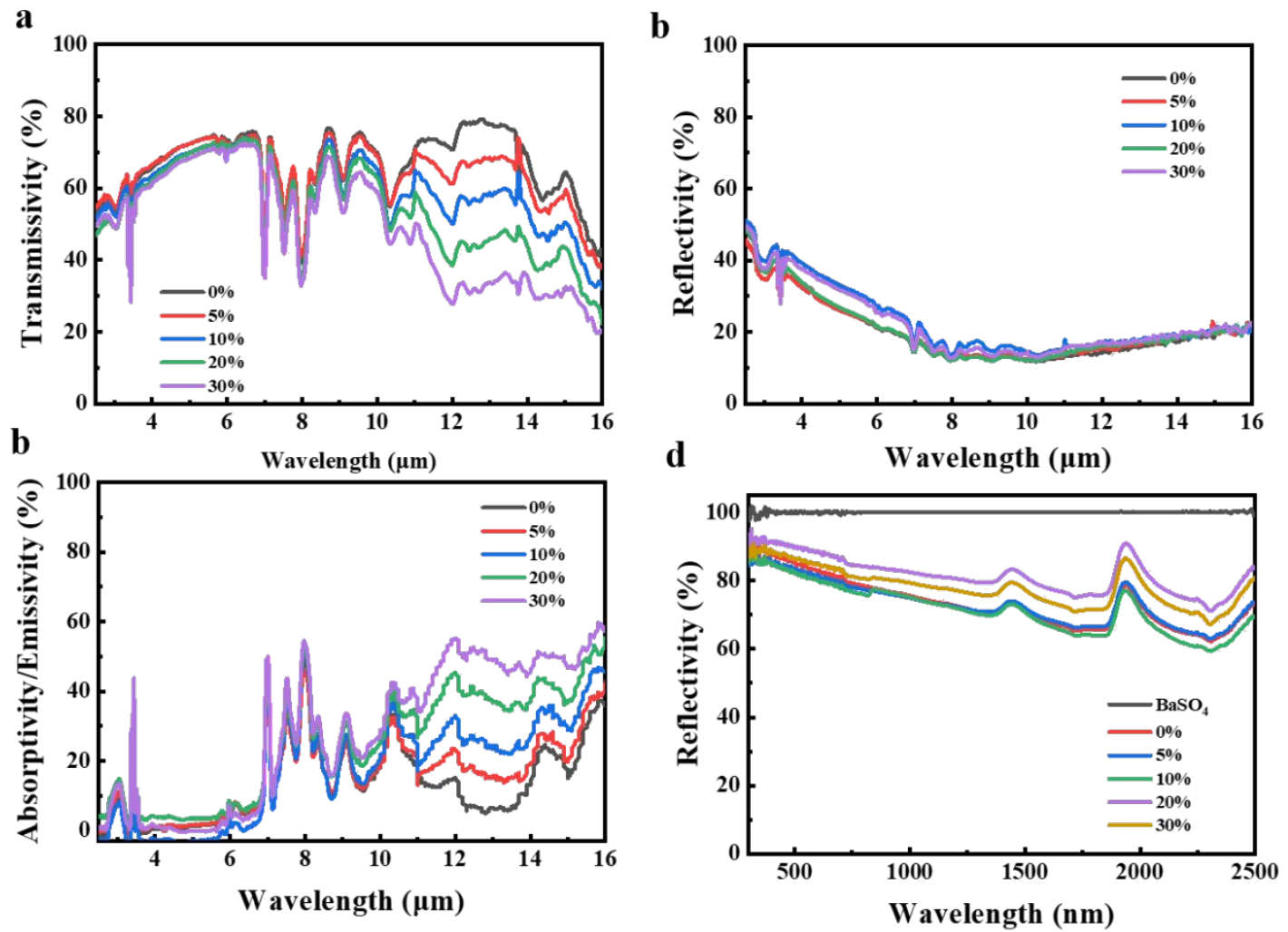

Figure S2. (a) IR transmissivity, (b) IR reflectivity, (c) IR absorptivity/emissivity and (d) UV-VIS-NIR reflectivity spectra of the $\mathrm{CA} / \mathrm{Al}_{2} \mathrm{O}_{3} \mathrm{NFM}$ with different mass ratios of $\mathrm{Al}_{2} \mathrm{O}_{3}$. The results showed that the optimal mass ratio of $\mathrm{Al}_{2} \mathrm{O}_{3}$ was $20 \%$.
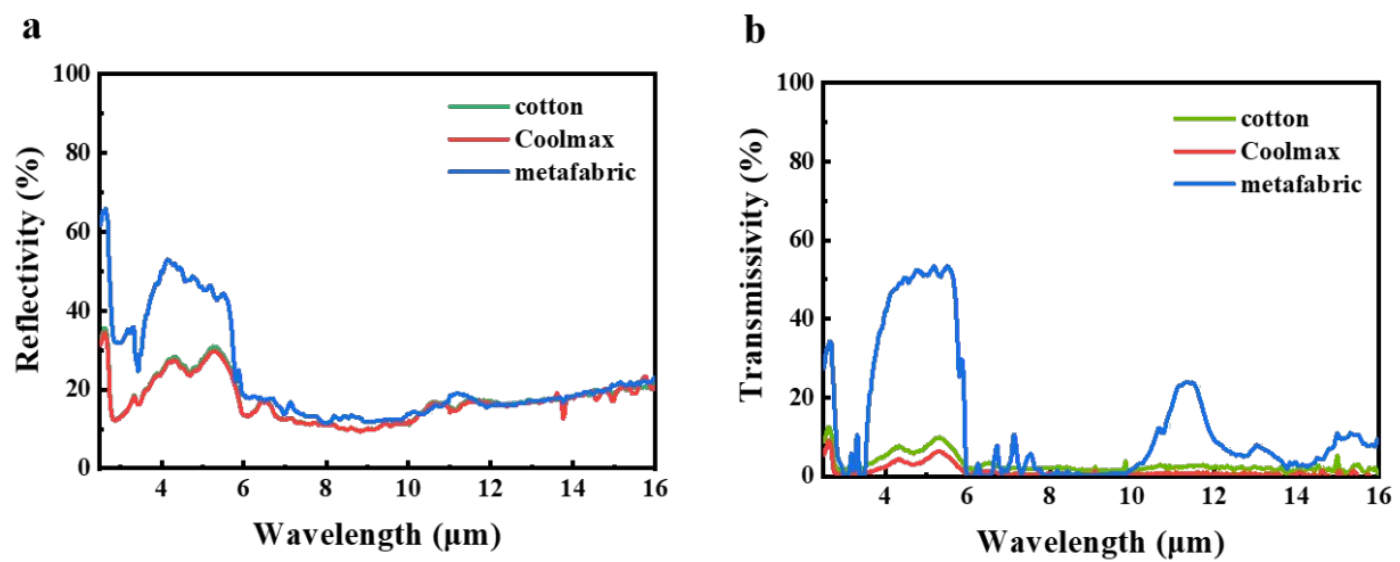

Figure S3. (a) IR reflectivity and (b) IR transmissivity spectra of cotton, Coolmax and the hierarchical metafabric. 
a

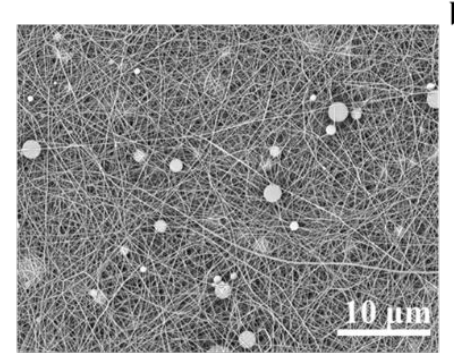

d

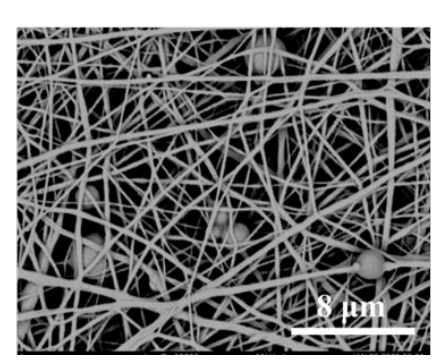

\section{b}
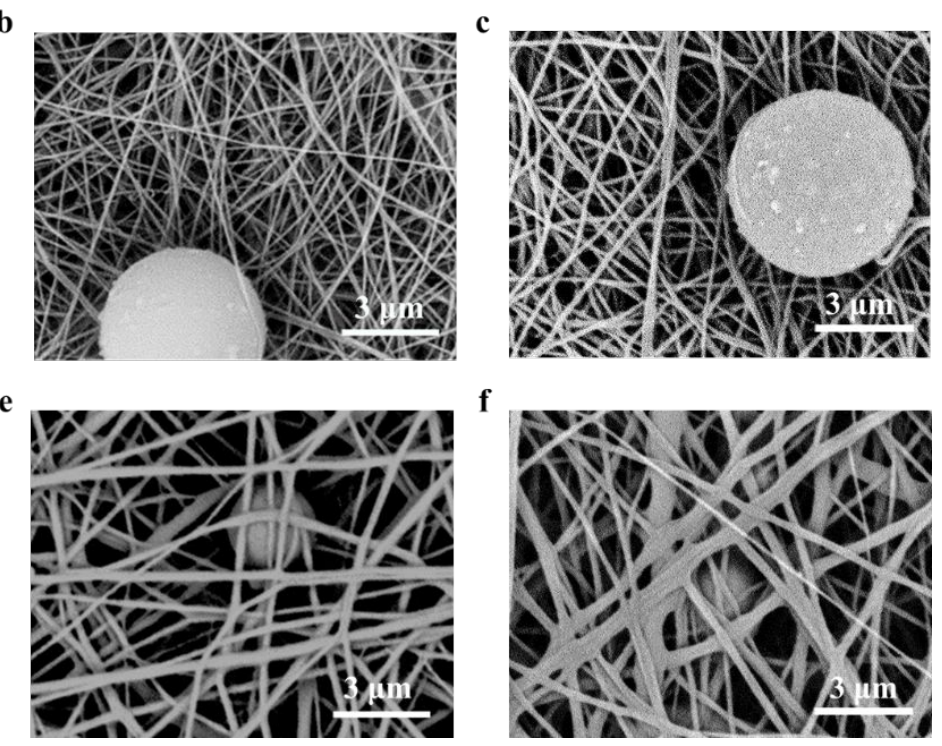

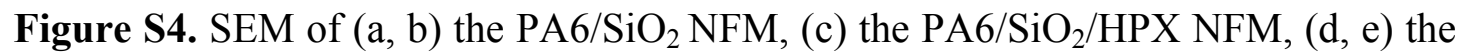
$\mathrm{CA} / \mathrm{Al}_{2} \mathrm{O}_{3} \mathrm{NFM}$, and (f) the $\mathrm{CA} / \mathrm{Al}_{2} \mathrm{O}_{3} / \mathrm{HPX} \mathrm{NFM}$.

a

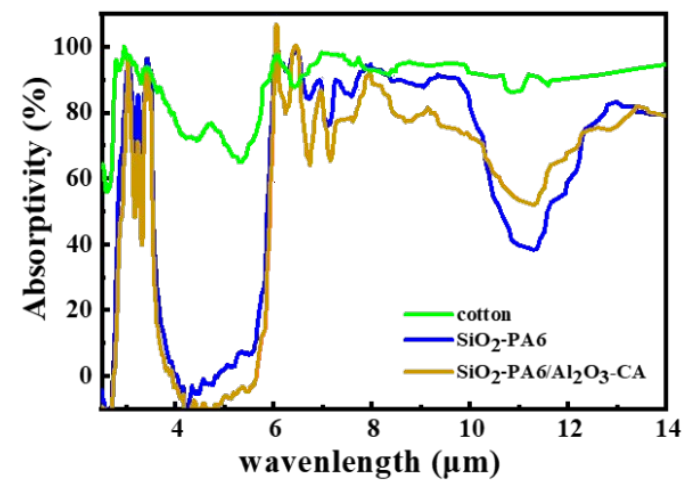

b

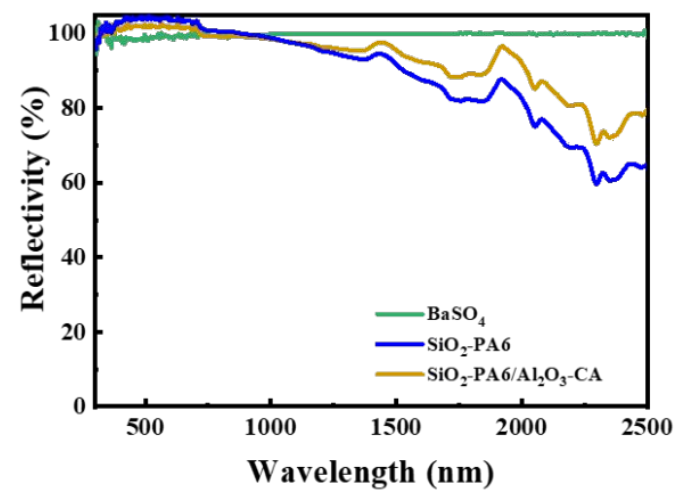

Figure S5. (a) IR absorptivity/emissivity and (b) UV-VIS-NIR reflectivity spectra of the PA6/SiO 2 NFM and the $\mathrm{PA} 6 / \mathrm{SiO}_{2} / \mathrm{CA} / \mathrm{Al}_{2} \mathrm{O}_{3}$ NFM. The superposition of the $\mathrm{CA} / \mathrm{Al}_{2} \mathrm{O}_{3}$ layer optimized the efficiency of the spectral response and further improved the cooling effect. 
a

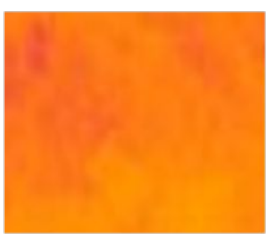

bare skin

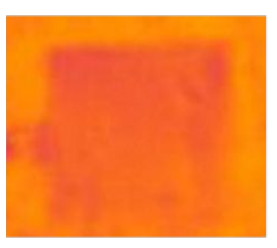

metafabric

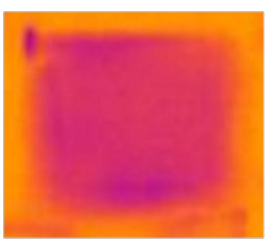

cotton

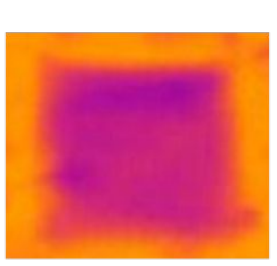

Coolmax

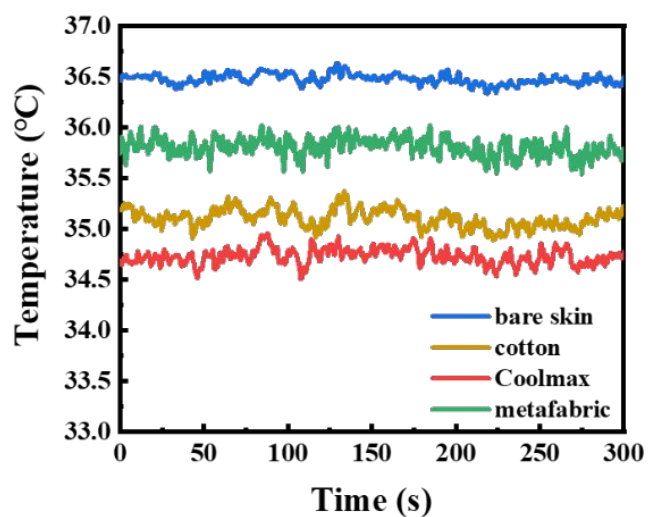

Figure S6. (a) Indoor thermal images of the simulated bare skin, the hierarchical metafabric, Coolmax and cotton. The samples were placed on a $37{ }^{\circ} \mathrm{C}$ hot stage to simulate covering the fabric on human skin. After the temperature had stabilized for a period of time, the thermal image of hierarchical metafabric appeared the warmest among the samples. (b) Schematic of the measurement device. (c) The outer surface temperature of the fabrics covered on the simulated skin. 


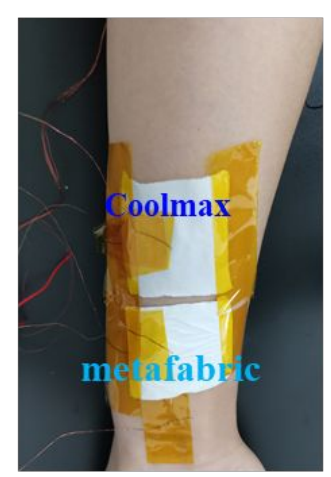

c

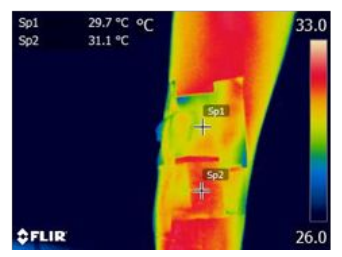

b

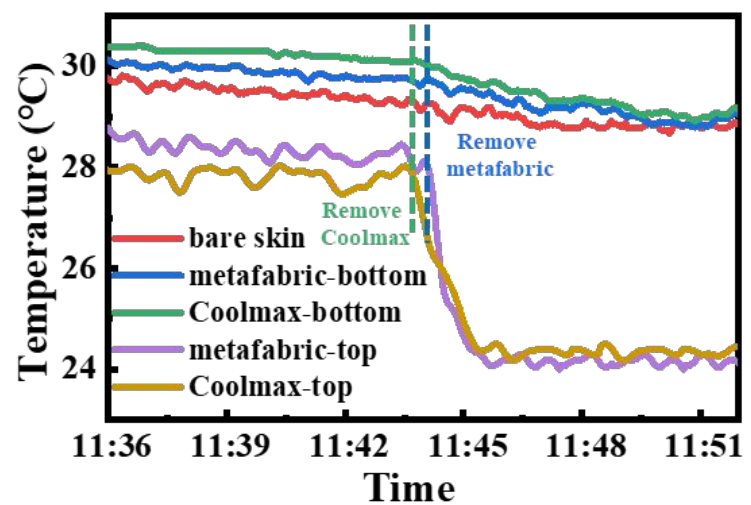

d

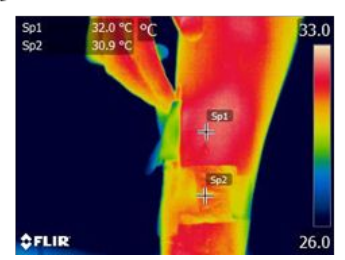

e

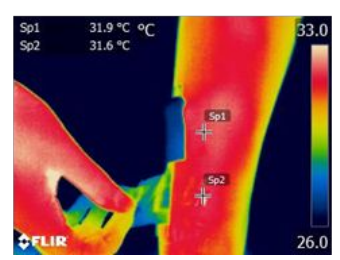

Figure S7. (a) Photograph of the indoor cooling performance test using thermocouples above and below the fabrics. (b) The temperature measurement results of the bare skin, the metafabric and Coolmax (indoor ambient temperature $19.6{ }^{\circ} \mathrm{C}$ ). With a similar thickness to the Coolmax, the metafabric merely increased the skin temperature by $\sim 0.5$ ${ }^{\circ} \mathrm{C}$, while the Coolmax increased the skin temperature by $\sim 1.0^{\circ} \mathrm{C}$, and the temperature of the top surface of the Coolmax was $\sim 0.52{ }^{\circ} \mathrm{C}$ lower than that of the metafabric. The reason is that metafabric has better infrared transmission performance than Coolmax, thus can better dissipate the human heat. (c-e) IR thermal image. The thermal image of Coolmax appeared colder than the metafabric, indicating better infrared transmission performance of the metafabric, which was in consistent with thermocouple measurement results. When the fabrics were removed, the thermal image of the skin covered by Coolmax appeared warmer than that of the metafabric, due to that Coolmax blocked more heat than the metafabric did. 

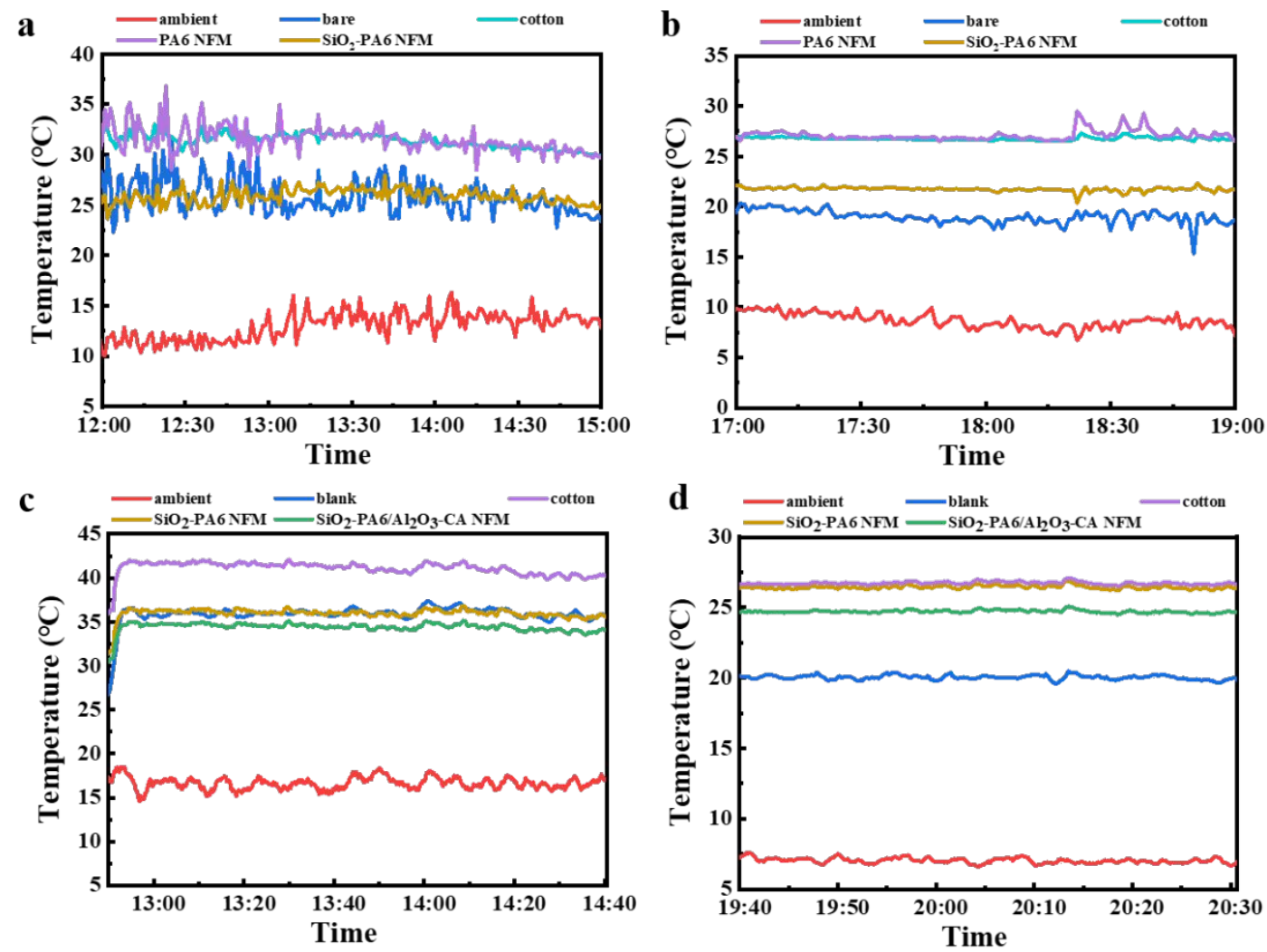

Figure S8. Comparison of the temperatures measured with different textile-covered (a, c) in the day and (b, d) at night without convection. Experiments proved that the addition of $\mathrm{SiO}_{2}$ and the superposition of the $\mathrm{CA} / \mathrm{Al}_{2} \mathrm{O}_{3}$ layer improved the cooling effect. 


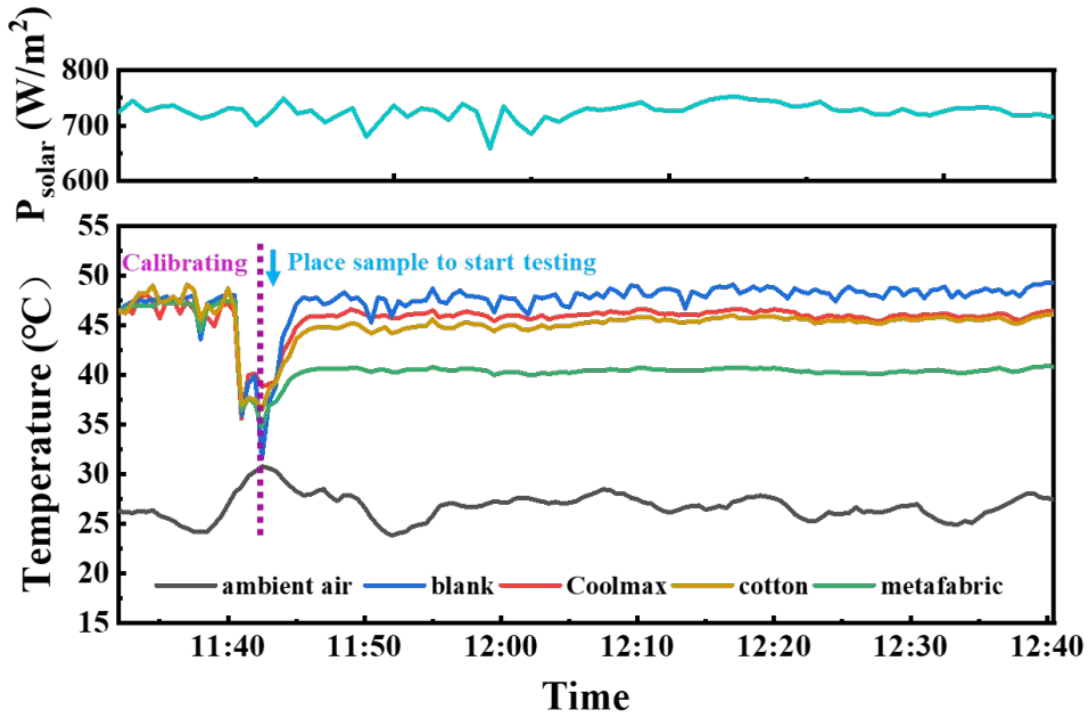

Figure S9. Daytime temperature measured with the hierarchical metafabric-covered, cotton-covered, Coolmax-covered, and non-covered without convection. In order to reduce the influence of internal convection and the thermocouple on the experimental results, we measured the temperature for a short period of time without fabric covering during 11:30AM to 11:40AM. Then the PE film was removed (temperature significantly changed at this point) in order to place the fabric samples. And we placed the samples to start the test at around 11:43AM.

As shown in Figure S10, we used one-dimensional steady-state heat transfer model analysis to determine the additional cooling power demand by the skin to achieve the skin temperature of $34{ }^{\circ} \mathrm{C}$ at the outdoor or indoor conditions.

For textile covered skin, the energy balance equations at the skin surface can be expressed as: 


$$
\begin{aligned}
& q_{\text {gen }}-q_{\text {cool }}=-\frac{\tau_{\text {tex } x \text { is }} \cdot\left(1-\rho_{\text {skin, vis }}\right)}{1-\rho_{\text {tex }, \text { vis }} \cdot \rho_{\text {skin, }, i s}} \cdot q_{\text {sun }}+\frac{\left(1-\rho_{\text {tex }, i r}\right)}{1-\rho_{\text {tex }, i r} \cdot \rho_{\text {skin, }, i r}} \cdot q_{\text {rad,s }}- \\
& \frac{\tau_{\text {tex }, i r} \cdot\left(1-\rho_{\text {skin, }, i r}\right)}{1-\rho_{\text {tex }, i r} \cdot \rho_{\text {skin, }, i r}} \cdot q_{\text {rad.e }}-\frac{\left(1-\rho_{\text {skin, }, r}\right)}{1-\rho_{\text {tex }, i r} \cdot \rho_{\text {skin, }, i r}} \cdot q_{\text {rad,tex } 1}+q_{\text {cond,air } 1}+q_{\text {conv } 1}
\end{aligned}
$$

Here, $q_{g e n}$ is the metabolic heat generation rate per unit area, $q_{c o o l}$ is the additional cooling power supply. $q_{\text {sun }}$ is solar irradiance. $q_{r a d, s}$ is the radiative heat flux from the skin, $q_{\text {rad.e }}$ is the radiative heat flux from the ambient air, $q_{\text {rad,tex } 1}$ is the radiative heat flux from the textile inner surface, $q_{\text {cond,air } 1}$ is the conductive heat flux in the air gap between the skin and the textile. $q_{\operatorname{conv} 1}$ is the convective heat flux in the air gap between the skin and the textile. $\rho_{v i s}$ is UV-VIS-NIR reflectance, $\varepsilon_{v i s}$ is UV-VISNIR emittance, and $\tau_{v i s}$ is UV-VIS-NIR transmittance. $\rho_{i r}$ is MIR reflectance, $\varepsilon_{\text {ir }}$ is MIR emittance, and $\tau_{i r}$ is MIR transmittance. Since the skin is assumed to be thick, the transmittance can be ignored. The term $\left(1-\rho_{\text {skin,vis }}\right)$ and $\left(1-\rho_{\text {skin,ir }}\right)$ represent the absorptance of the skin for VIS and IR and they can be replaced by $\varepsilon_{\text {skin,vis }}$ and $\varepsilon_{\text {skin,ir. }}$ Based on Fourier's law, Newton's law of cooling and the Stefan-Boltzmann law, the conductive, convective and radiative heat flux terms can be expressed as,

$$
\begin{gathered}
q_{\text {rad,s }}=\varepsilon_{\text {skin }, i r} \sigma T_{\text {skin }}^{4} \\
q_{\text {rad,e }}=\varepsilon_{e, i r} \sigma T_{e}^{4} \\
q_{\text {rad,tex } 1}=\varepsilon_{\text {tex,ir }} \sigma T_{\text {tex } 1}^{4} \\
q_{\text {cond,air } 1}=k_{\text {air }} \cdot\left(\frac{T_{\text {skin }}-T_{\text {tex } 1}}{t_{\text {air }}}\right) \\
q_{\text {conv }}=h \cdot\left(T_{\text {skin }}-T_{\text {tex } 1}\right)
\end{gathered}
$$

$k_{\text {air }}$ is thermal conductivity of $\operatorname{air}\left(\mathrm{W} \cdot \mathrm{m}^{-1} \cdot \mathrm{K}^{-1}\right), t_{\text {air }}$ is thickness between the skin 
$(\mu \mathrm{m})$ and the textile, $\sigma$ is Stefan-Boltzmann constant $\left(5.67 \times 10^{-8} \mathrm{~W} \cdot \mathrm{m}^{-2} \cdot \mathrm{K}^{-4}\right)$ and $h$ is convective heat transfer coefficients.

In outdoor and under sunlight, the solar is the main heat source for human, thermal radiation only occupy a small proportion of entire heat loss of human body when the ambient temperature is above $30^{\circ} \mathrm{C}$. Therefore, the fabric needs to have high sunlight reflection performance and the metafabric meets this requirement.

At the indoor or night conditions, we carried out night-time cooling tests outdoors. The schematic diagram of the temperature measuring setup and the results (which were in consistent with Figure 2d) were shown in the Figure S11. The surrounding insulation baffle and the top polyethylene film were aim to reduce convection, so the convection was relatively weak in this configuration and we assumed that $\mathrm{q}_{\mathrm{conv}} \approx 0$.

We input value $\left(\mathrm{q}_{\mathrm{gen}}=58 \mathrm{~W} / \mathrm{m}^{2}, \varepsilon_{\mathrm{skin}}=98 \%, \varepsilon_{\mathrm{e}} \approx 100 \%, \varepsilon_{\text {metafabric }}=78.13 \%, \varepsilon_{\text {Coolmax }}=\right.$ $86.06 \%, \tau_{\text {metafaric }}=7.1 \%, \tau_{\text {Coolmax }}=0.5 \%, \rho_{\text {metafabric }}=14.77 \%, \rho_{\text {Coolmax }}=13.44 \%$, $\left.\mathrm{T}_{\text {metafabric }} \approx 24.1^{\circ} \mathrm{C}, \mathrm{T}_{\text {Coolmax }} \approx 25.4{ }^{\circ} \mathrm{C}, \mathrm{T}_{\text {ambient }} \approx 18.2^{\circ} \mathrm{C}, \mathrm{q}_{\text {cond,air }} \approx 0\right)$ into equations (1), (2), (3), (4) and (5) to calculate $\mathrm{q}_{\mathrm{cool}}$. The results were $\mathrm{q}_{\text {cool, metafabric }} \approx 3.50 \mathrm{~W} / \mathrm{m}^{2}, \mathrm{q}_{\text {cool, }}$, Coolmax $\approx 11.54 \mathrm{~W} / \mathrm{m}^{2}$ and $\mathrm{q}_{\text {cool, skin }} \approx-36.50 \mathrm{~W} / \mathrm{m}^{2}$.

The covering fabric blocks the heat loss from the skin, but the metafabric is less effective than commercial fabrics in blocking heat. 


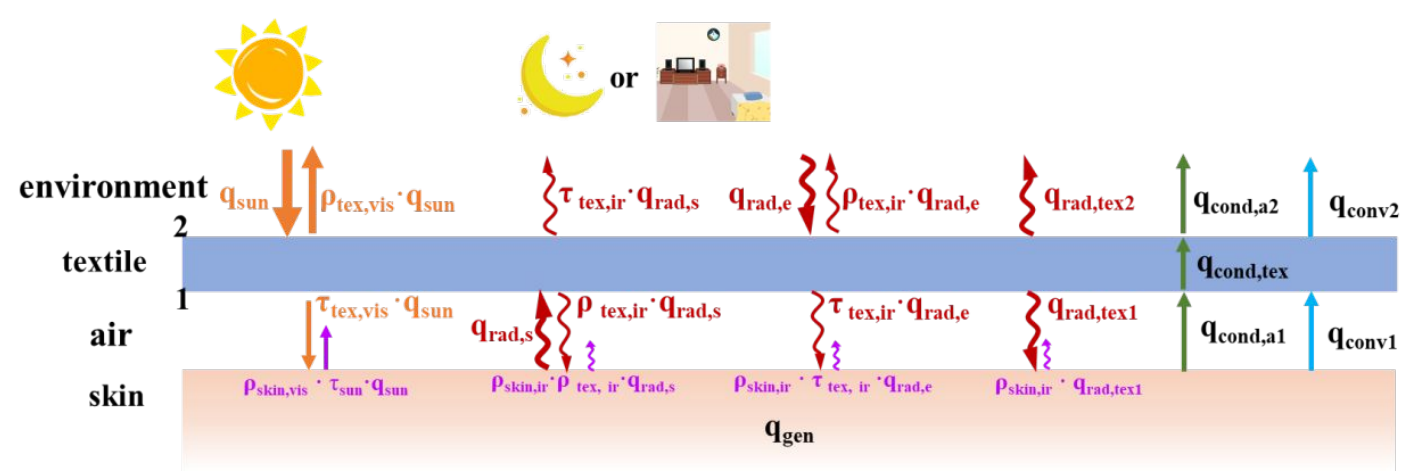

Figure S10. Heat transfer model was developed to analyze heat dissipation from a clothed human body to the ambient environment.

a

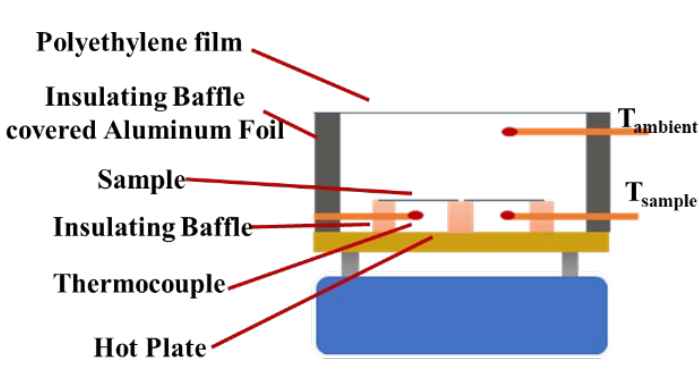

b

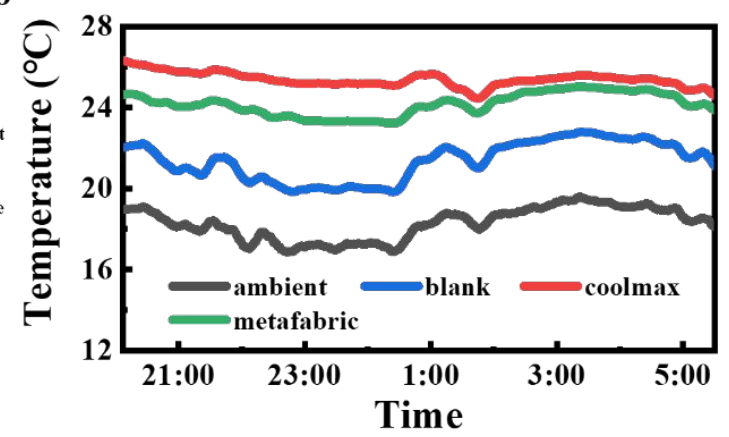

Figure S11. (a) Schematic diagram of temperature measuring setup. (b) Night cooling performance test.

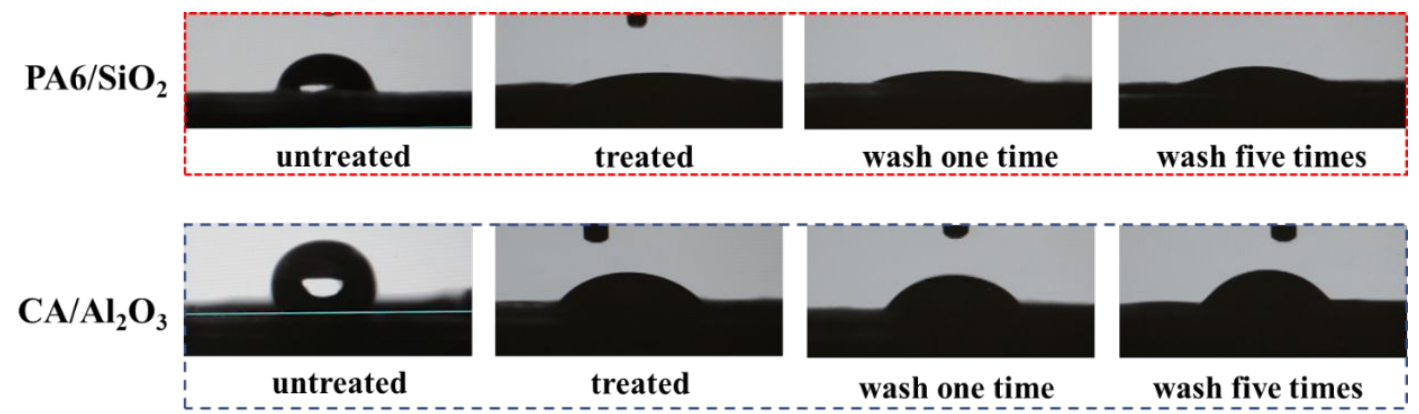

Figure S12. WCAs of the $\mathrm{PA} 6 / \mathrm{SiO}_{2}$ and $\mathrm{CA} / \mathrm{Al}_{2} \mathrm{O}_{3}$ layer after washing $0,1,5$ times. 

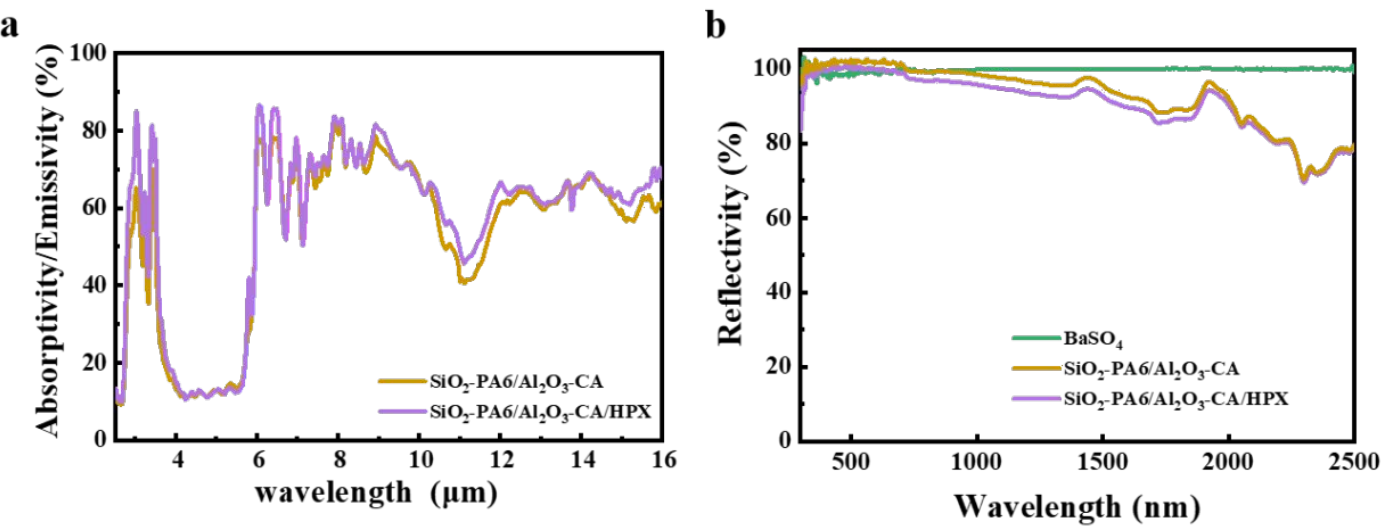

Figure S13. Comparison of (a) IR absorptivity/emissivity and (b) UV-VIS-NIR reflectivity spectra of the $\mathrm{PA} 6 / \mathrm{SiO}_{2} / \mathrm{CA} / \mathrm{Al}_{2} \mathrm{O}_{3} \mathrm{NFM}$ before and after surface modification.

a

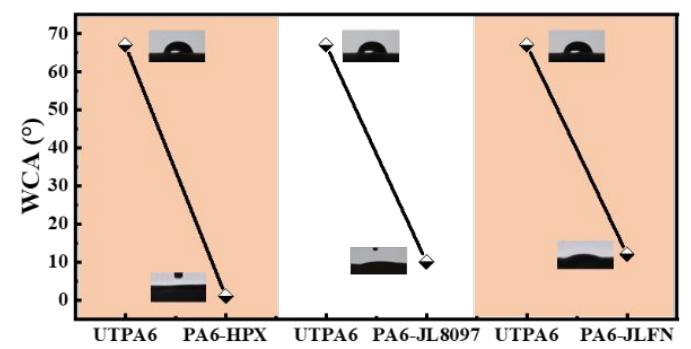

b

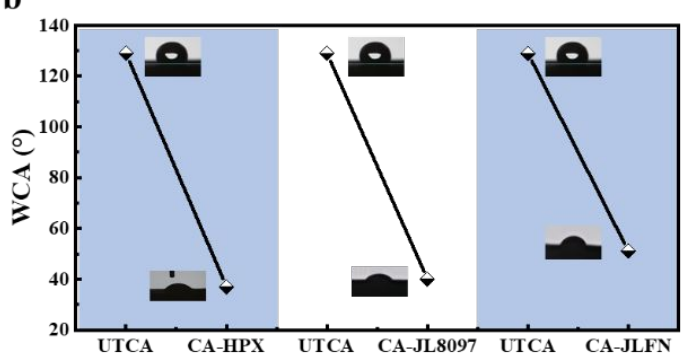

Figure S14. (a) WCAs of untreated $\mathrm{PA} 6 / \mathrm{SiO}_{2}$ (UTPA6) and $\mathrm{PA} / \mathrm{SiO}_{2}$ treated with different moisture control agents (HPX, JL8097, JLFN). (b) WCAs of untreated $\mathrm{CA} / \mathrm{Al}_{2} \mathrm{O}_{3}$ (UTCA) and treated $\mathrm{CA} / \mathrm{Al}_{2} \mathrm{O}_{3}$ with different moisture control agents (HPX, JL8097, JLFN). 
a

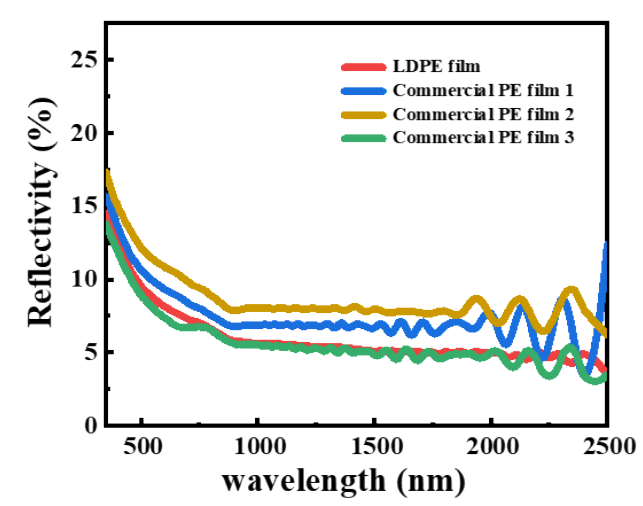

b

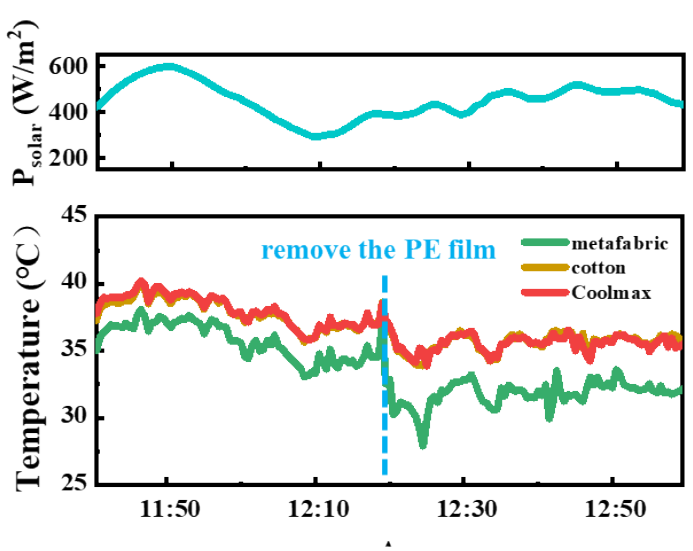

Figure S15. (a) UV-VIS-NIR reflectivity spectra of different polyethylene films. (b)

The temperature change of the fabrics before and after removing the polyethylene film.

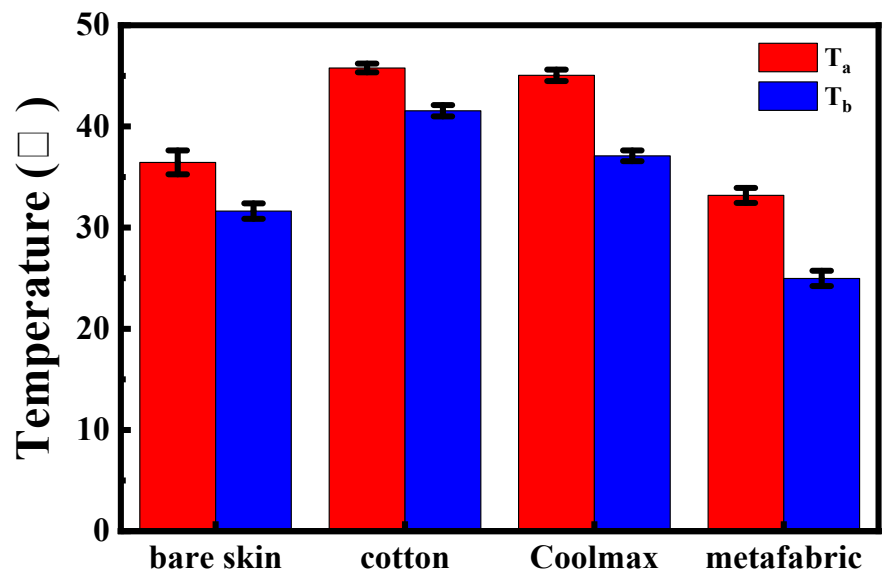

Figure S16. Diagram of average temperature before and after sweat evaporation. $T_{a}$ is the time-averaged temperature from 13:30 to 14:24, the error bars represent standard deviation of 170 measured data; $T_{b}$ is the time-averaged temperature from 14:46 to 15:10, the error bars represent standard deviation of 50 measured data. 
$\mathbf{a}$

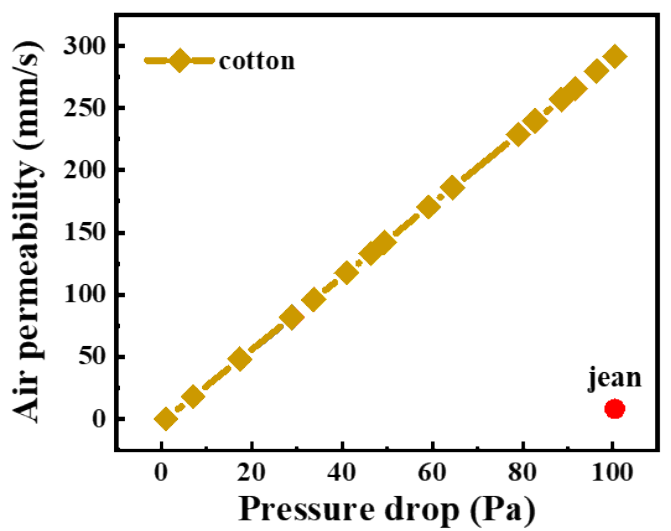

b

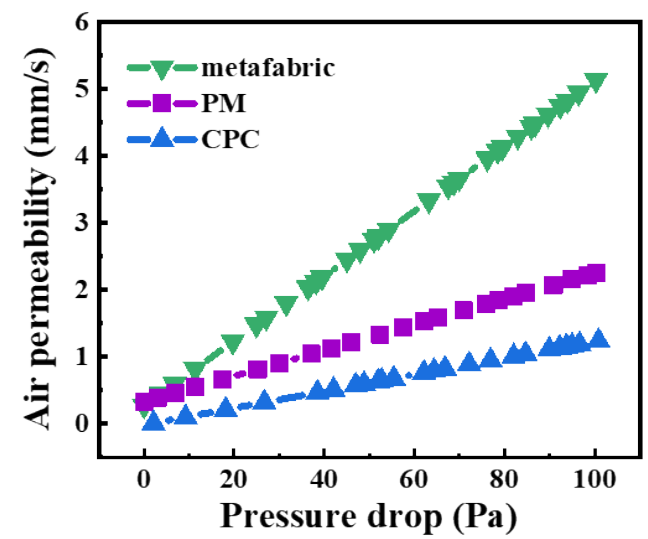

Figure S17. Air permeability showing the textile allows the passage of air. (a) cotton and jean. (b) the metafabric, PM, and CPC.

a

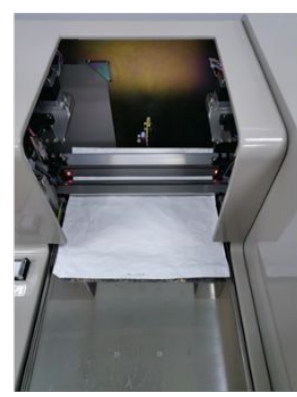

b

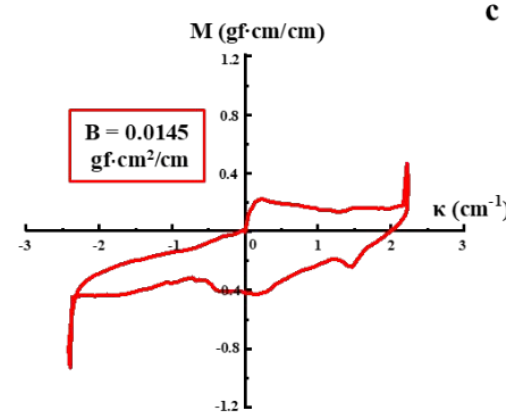

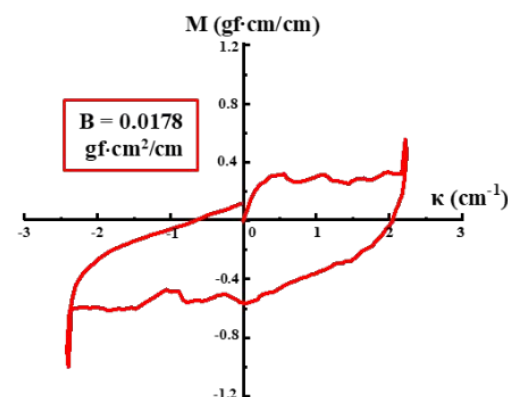

Figure S18. (a) Photograph of blending performance test. Bending cycle curve of (b)

PA6 nanofiber fabric and (c) $\mathrm{PA} 6 / \mathrm{SiO}_{2}$ nanofiber fabric. $\mathrm{M}$ is bending moment and $\kappa$ is bending rate. Bending stiffness (B) indicates the ability of the fabric to resist bending deformation. $B=\frac{B_{f}+B_{b}}{2}, B_{f}$ and $B_{b}$ are respectively the average slope of the bending cycle curve at the bending rate $\kappa=0.5 \sim 1.5$ and $\kappa=-0.5 \sim-1.5$. 
a
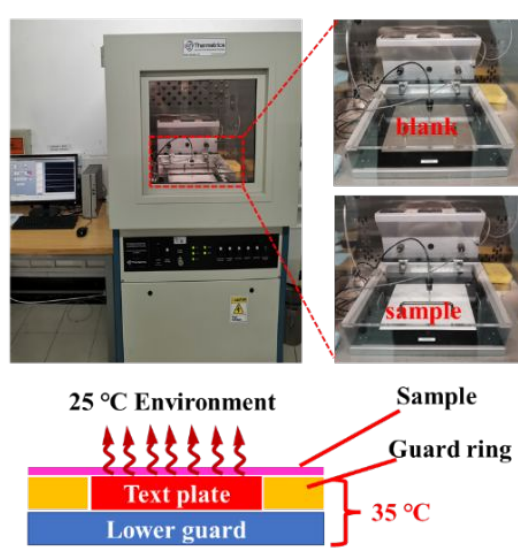
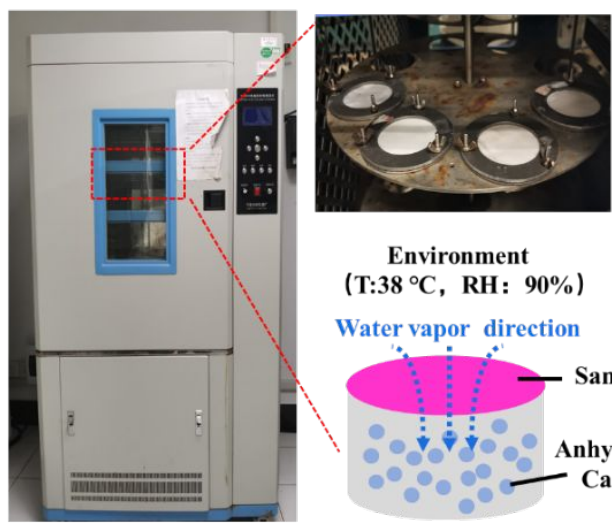

Environment ( T:38 ${ }^{\circ} \mathrm{C}$, RH: $90 \%$ )

Water vapor direction

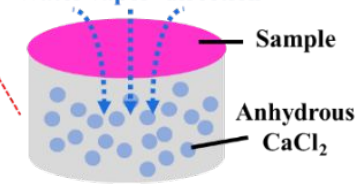

e

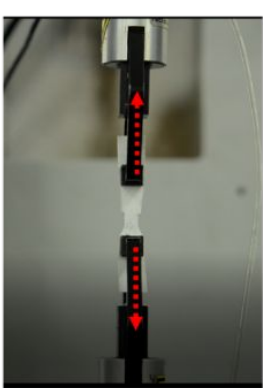

Figure S19. (a) Thermal resistance was assessed according to GB/T 11048-2018 standard using a sweating guarded hotplate and schematic diagram of thermal resistance test. (b) Water vapor transmission rate was measure by fabric moisture permeability testing apparatus (YG601H, Ningbo Textile Instrument Factory, China) followed by GB/T 12704.1-2009 standard. (c) Air permeability was measured by the air permeability tester (YG461E, Wenzhou Fangyuan Instrument Co., Ltd., China) followed by GB/T 24218.15-2018 standard. The test was carried out at a pressure of $100 \mathrm{~Pa}$ with the machine orifice area of $20 \mathrm{~cm}^{2}$. (d) Tear force measurement of trousershaped test specimens (single tear method) according to GB/T 3917.3-2009 using electronic universal material testing machine (3369, Instron Inc., USA). (e) Tensile strength and force were gained utilizing a tensile tester (5969, Instron Inc., USA). 


\section{Supporting Table}

Table S1. Summary of intelligent fabric materials.

\begin{tabular}{|c|c|c|c|}
\hline Materials & Reference & Working principle & Performance \\
\hline \multirow{2}{*}{$\begin{array}{l}\text { Nanoporous } \\
\text { membrane }\end{array}$} & Hsu et $\mathrm{al}^{1}$ & Mid-IR transparent & $\begin{array}{l}2.7{ }^{\circ} \mathrm{C} \text { and } 2.0{ }^{\circ} \mathrm{C} \text { lower skin } \\
\text { temperature when covered with } \\
\text { nanoPE cloth and with processed } \\
\text { nanoPE cloth, respectively, than } \\
\text { when covered with cotton indoor. }\end{array}$ \\
\hline & Hsu et $\mathrm{al}^{2}$ & Mid-IR emissive & $\begin{array}{l}\text { When the surface with high } \\
\text { emissivity facing outside, the textile } \\
\text { brought about } 3.1^{\circ} \mathrm{C} \text { cooling effect } \\
\text { compare to traditional textile indoor. }\end{array}$ \\
\hline \multirow{2}{*}{$\begin{array}{l}\text { Nanofiber } \\
\text { membrane }\end{array}$} & Xiao et $\mathrm{al}^{3}$ & Mid-IR emissive & $\begin{array}{l}0.4-1.7^{\circ} \mathrm{C} \text { lower skin temperature } \\
\text { than those of commercial textiles } \\
\text { indoor. }\end{array}$ \\
\hline & Song et $\mathrm{al}^{4}$ & $\begin{array}{l}\text { Solar-reflecting and } \\
\text { mid-IR emissive }\end{array}$ & $\begin{array}{l}\text { The composite textile decreased the } \\
\text { temperature of the human body by } \\
4.5-6.5^{\circ} \mathrm{C} \text { under direct sunlight. }\end{array}$ \\
\hline \multirow{5}{*}{$\begin{array}{l}\text { Microfiber } \\
\text { fabric }\end{array}$} & Peng et $\mathrm{al}^{5}$ & Mid-IR transparent & $\begin{array}{l}2.3{ }^{\circ} \mathrm{C} \text { lower skin temperature than } \\
\text { conventional cotton fabric indoor. }\end{array}$ \\
\hline & $\mathrm{Hu}$ et $\mathrm{al}^{6}$ & Mid-IR transparent & $\begin{array}{l}\text { Intelligent fabric allowed the } \\
\text { microenvironment temperature } \\
\text { between the skin and clothing to } \\
\text { drop at least } \sim 2.5^{\circ} \mathrm{C} \text { compared with }\end{array}$ \\
\hline & & & cotton fabrics. \\
\hline & Cai et $\mathrm{al}^{7}$ & $\begin{array}{l}\text { Solar-reflecting and } \\
\text { mid-IR transparent }\end{array}$ & $\begin{array}{l}\text { The textile enabled simulated skin to } \\
\text { avoid overheating by } 5-13{ }^{\circ} \mathrm{C} \\
\text { compared to normal textile under } \\
\text { direct sunlight. }\end{array}$ \\
\hline & Zeng et $\mathrm{al}^{8}$ & $\begin{array}{l}\text { Solar-reflecting and } \\
\text { Mid-IR emissive }\end{array}$ & $\begin{array}{l}\text { The metafabric could be cooled } \\
\text { down } \sim 4.8^{\circ} \mathrm{C} \text { lower than that } \\
\text { covered by commercial cotton } \\
\text { fabric under direct sunlight. }\end{array}$ \\
\hline
\end{tabular}




\begin{tabular}{|c|c|c|c|}
\hline Coating fabric & Wei et $\mathrm{al}^{9}$ & Solar-Reflecting & $\begin{array}{l}\text { The textile reduced the temperature } \\
\text { of simulated skin by } 2.3-8{ }^{\circ} \mathrm{C} \\
\text { compared to that of an unmodified } \\
\text { reference. }\end{array}$ \\
\hline $\begin{array}{l}\text { Hierarchical } \\
\text { metafabric }\end{array}$ & This work & $\begin{array}{l}\text { Solar-Reflecting, } \\
\text { Mid-IR Emissive } \\
\text { and Moisture- } \\
\text { wicking }\end{array}$ & $\begin{array}{l}\text { The hierarchical metafabric enabled } \\
\text { simulated skin to prevent } \\
\text { overheating by } 16.6^{\circ} \mathrm{C} \text { compared to } \\
\text { traditional textile and in which the } \\
\text { management of humidity further } \\
\text { improved the cooling performance } \\
\text { by } \sim 8.2^{\circ} \mathrm{C} \text {. }\end{array}$ \\
\hline
\end{tabular}

\section{References:}

1. Hsu, P.-C.; Song, A. Y.; Catrysse, P. B.; Liu, C.; Peng, Y.; Xie, J.; Fan, S.; Cui, Y., Radiative human body cooling by nanoporous polyethylene textile. Science 2016, 353 (6303), 1019-1023.

2. Hsu, P.-C.; Liu, C.; Song, A. Y.; Zhang, Z.; Peng, Y.; Xie, J.; Liu, K.; Wu, C.-L.; Catrysse, P. B.; Cai, L.; Zhai, S.; Majumdar, A.; Fan, S.; Cui, Y., A dual-mode textile for human body radiative heating and cooling. Sci. Adv. 2017, 3 (11), e1700895.

3. Xiao, R.; Hou, C.; Yang, W.; Su, Y.; Li, Y.; Zhang, Q.; Gao, P.; Wang, H., Infraredradiation-enhanced nanofiber membrane for sky radiative cooling of the human body. ACS Appl. Mater. Interfaces 2019, 11 (47), 44673-44681.

4. Song, Y. N.; Li, Y.; Yan, D. X.; Lei, J.; Li, Z. M., Novel passive cooling composite textile for both outdoor and indoor personal thermal management. Compos. Part A Appl. Sci. Manuf. 2020, 130 (C), 105738.

5. Peng, Y.; Chen, J.; Song, A. Y.; Catrysse, P. B.; Hsu, P.-C.; Cai, L.; Liu, B.; Zhu, Y.; Zhou, G.; Wu, D. S.; Lee, H. R.; Fan, S.; Cui, Y., Nanoporous polyethylene microfibres for large-scale radiative cooling fabric. Nat. Sustain. 2018, 1 (2), 105-112. 6. Hu, X.; Tian, M.; Xu, T.; Sun, X.; Sun, B.; Sun, C.; Liu, X.; Zhang, X.; Qu, L., Multiscale disordered porous fibers for self-sensing and self-cooling integrated smart sportswear. ACS Nano 2020, 14 (1), 559-567.

7. Cai, L.; Song, A. Y.; Li, W.; Hsu, P.-C.; Lin, D.; Catrysse, P. B.; Liu, Y.; Peng, Y.; Chen, J.; Wang, H.; Xu, J.; Yang, A.; Fan, S.; Cui, Y., Spectrally selective nanocomposite textile for outdoor personal cooling. Adv. Mater. 2018, 30 (35), 1802152. 
8. Zeng, S.; Pian, S.; Su, M.; Wang, Z.; Wu, M.; Liu, X.; Chen, M.; Xiang, Y.; Wu, J.; Zhang, M.; Cen, Q.; Tang, Y.; Zhou, X.; Huang, Z.; Wang, R.; Tunuhe, A.; Sun, X.; Xia, Z.; Tian, M.; Chen, M.; Ma, X.; Yang, L.; Zhou, J.; Zhou, H.; Yang, Q.; Li, X.; Ma, Y.; Tao, G., Hierarchical-morphology metafabric for scalable passive daytime radiative cooling. Science 2021, 373 (6555), 692-700.

9. Wei, W.; Zhu, Y.; Li, Q.; Cheng, Z.; Yao, Y.; Zhao, Q.; Zhang, P.; Liu, X.; Chen,

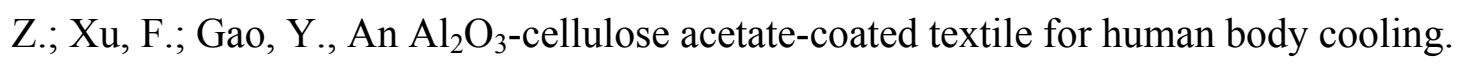
Sol. Energy Mate. Sol. Cells 2020, 211, 110525.

Table S2. Filtration efficiencies of different samples.

\begin{tabular}{ccccc}
\hline \multirow{2}{*}{ Sample } & \multicolumn{3}{c}{ test number } & average value \\
\cline { 2 - 5 } & 1 & 2 & 3 \\
The metafabric & 88.9 & 95.5 & 92.9 & 92.4 \\
The protective metafabric & 74.1 & 74.4 & 73.9 & 74.1 \\
\hline
\end{tabular}

